\title{
MicroRNAs e seu papel no desenvolvimento embrionário
}

\author{
MicroRNAs and its role in embryonic development
}

\author{
Vinicius Farias Campos ${ }^{\mathrm{I}}$ Gabriel Urtiaga $^{\mathrm{I}}$ Breno Gonçalves $^{\mathrm{I}}$ João Carlos Deschamps ${ }^{\mathrm{I}}$ \\ Tiago Collares ${ }^{\mathrm{I}}$
}

\section{- REVISÃO BIBLIOGRÁFICA -}

\section{RESUMO}

MicroRNAs (miRNAs) são pequenas moléculas de RNA com aproximadamente 22 nucleotídeos incapazes de codificar proteinas e que apresentam função na regulação pós-transcricional da expressão gênica. Vários estudos vêm demonstrando o importante papel dos miRNAs na regulação do desenvolvimento embrionário de diferentes espécies, desde o controle da expressão de RNAs mensageiros durante o desenvolvimento inicial embrionário até a determinação de linhagens celulares durante a organogênese. Esta revisão irá abordar os principais miRNAs e seu papel na biologia reprodutiva, com ênfase no desenvolvimento embrionário de mamiferos.

Palavras-chave: microRNA, expressão gênica, silenciadores gênicos, desenvolvimento embrionário, mamiferos.

\section{ABSTRACT}

MicroRNAs (miRNAs) are small RNA molecules with around 22 nucleotides that are unable to encode proteins and play a key role on post-transcription regulation process. Several studies have demonstrated the relevant role of miRNAs on the regulation of embryonic development on different species, from the control of gene expression during the early embryo development to determination of cellular lineages over the organogenesis. This review will present the miRNAs and its role on reproductive biology focusing on the mammalian embryo development.

Key words: microRNA, gene expression, gene silencing, embryo development, mammalian.

\section{INTRODUÇÃO}

MicroRNAs (miRNAs) são pequenas moléculas de RNA com aproximadamente 22 nucleotídeos incapazes de codificar proteínas e que apresentam função na regulação pós-transcricional da expressão gênica, seja pela degradação ou pelo bloqueio na tradução de RNAs mensageiros (mRNAs). Esse processo exige a complementariedade parcial entre o miRNA e trechos da molécula de mRNA(BARTEL, 2004; TAY et al., 2008).

O primeiro relato sobre esse tipo de RNA surgiu em 1993 a partir da identificação de uma pequena região não-codificadora (lin-4), específica do nematoda Caenorhabditis elegans, que atua na regulação negativa dos níveis da proteína Lin-14, característica do desenvolvimento larval dessa espécie (LEE et al., 1993). Acreditava-se que esse era um mecanismo de regulação específico do $\boldsymbol{C}$. elegans. Entretanto, posteriormente, a descoberta do let-7 - outro microRNA envolvido com o tempo de desenvolvimento do C.elegans, porém conservado em uma grande variedade de organismos multicelulares - demonstrou que a regulação da expressão gênica pelos miRNAs não é restrita aos nematoides, sendo um mecanismo presente em muitos animais (PASQUINELLI et al., 2000; REINHART et al., 2000).

\footnotetext{
'Laboratório de Embriologia Molecular e Transgenese, Núcleo de Biotecnologia, Centro de Desenvolvimento Tecnológico, Universidade Federal de Pelotas (UFPel), Campus Universitário, s/no , CP 354, 96010-900, Pelotas, RS, Brasil. E-mail: fariascampos@gmail.com. *Autor para correspondência.
} 
Já foram identificados milhares de diferentes miRNAs, tecido-específicos ou não, muitos deles evolutivamente conservados. Acredita-se que o número de miRNAs presente no genoma de vertebrados seja muito superior ao conhecido atualmente e que participem da regulação de 20 a $30 \%$ dos genes (LEWIS et al., 2005; REN et al., 2009; WIENHOLDS et al., 2005).

MicroRNAs atuam na regulação de diversos processos biológicos, incluindo proliferação e diferenciação celular (TAY et al., 2008), neurogênese (LIU \& ZHAO, 2009; SMIRNOVA et al., 2005), angiogênese (NICOLI et al., 2010) e apoptose (HE et al., 2010). Esta revisão aborda os principais miRNAs e seu papel na biologia reprodutiva, com ênfase no desenvolvimento embrionário de mamíferos.

\section{Biogênese dos MicroRNAs}

A maior partes dos miRNAs são transcritos a partir de regiões do genoma diferentes daquelas tradicionalmente conhecidas por codificar proteínas, podendo inclusive se localizar em zonas de íntrons (LEE et al., 2006).

Os miRNAs de mamíferos são transcritos pela RNA polimerase II ou RNA polimerase III, originando um miRNA primário (pri-miRNA), formado por uma ou mais estruturas em forma de grampo. Esse produto apresenta de centenas a milhares de nucleotídeos e geralmente pode formar mais de um miRNA funcional. As duas RNAs polimerases reconhecem diferentes elementos promotores e terminadores, oferecendo uma ampla variedade de mecanismos regulatórios de sua atividade (BARTEL, 2004; DU \& ZAMORE, 2005; WINTER et al., 2009).

Os pri-miRNAs são processados/clivados por um complexo microprocessador nuclear composto pela enzima Drosha (um tipo de RNase III), pela proteína DGCR8 (a qual interage diretamente e de forma estável com o pri-miRNA, determinando a acurácia e a eficiência da clivagem) e por uma variedade de cofatores, responsáveis pela fidelidade, especificidade e/ou atividade da clivagem realizada pela Drosha. O produto do microprocessamento nuclear é o pre-miRNA (dsRNA), formado por $\sim 70$ nucleotídeos. O microprocessamento pelo complexo da Drosha não é obrigatório (BARTEL, 2004; DU \& ZAMORE, 2005; WINTER et al., 2009). Alguns pri-miRNAs intrônicos, após o processo de splicing, apresentam um tamanho apropriado e uma conformação de grampo semelhante a um pre-miRNA. Nesse caso, ignoram a clivagem pela Drosha e são levados diretamente ao citoplasma para serem novamente processados (RUBY et al., 2007).
Após a formação do pre-miRNA, este é protegido e transportado ao citoplasma em associação ao complexo Exportin-5-Ran-GTP-dependent (OKADA et al., 2009; SIOMI \& SIOMI, 2010). No citoplasma, o pre-miRNA é processado pelo complexo enzimático Dicer/TRBP/PACT, perdendo a configuração em "grampo" e originando duas fitas simples de miRNA de aproximadamente 22 nucleotídeos. Uma das fitas se liga a uma proteína Argonauta 2 e é preferencialmente acoplada ao complexo de proteínas que reprime a expressão do gene alvo, o RISC (RNA-induced silencing complex), enquanto a outra é degradada (BARTEL, 2004; LEE et al., 2006; SIOMI \& SIOMI, 2010). Estudos em outro RNA com papel de regulação pós-transcricional, o pequeno RNA de interferência (siRNA), indicam que a estabilidade termodinâmica das extremidades das duas fitas determinam qual das fitas será selecionada. Análises do perfil de estabilidade termodinâmica em precursores de miRNA sugerem que essa mesma regra pode ser aplicada para grande parte deles, porém não a todos (KIM et al., 2009). O RISC, contendo o microRNA, liga-se aos mRNAs-alvo, geralmente na 3'-UTR. No entanto, estudos recentes demonstraram que ele pode se ligar a qualquer outra região que apresente complementariedade, aumentando a diversidade de alvos de cada miRNA (TAY et al., 2008). A figura 1 esquematiza os eventos da biogênese e atuação dos miRNAs acima descritos.

Existe variação na expressão de miRNAs ao longo do desenvolvimento embrionário

Segundo HE et al. (2010), em camundongos, podemos dividir o padrão de expressão gênica inicial em três etapas distintas: primeira etapa (zigoto); segunda etapa (embrião com duas e quatro células); e, por fim, a terceira etapa, que corresponde aos estágios embrionários de 8 células, mórula e blastocisto. Já em humanos, embora ocorram três etapas também, a divisão temporal é distinta: primeira etapa (zigoto e embrião com duas e quatro células); segunda etapa (embrião com oito células); e finalmente a terceira etapa, que corresponde aos estágios embrionários de mórula e blastocisto.

Após a fertilização, transcritos maternos permanecem depositados no citoplasma do zigoto. Posteriormente, ocorre a degradação de tais transcritos, substituídos, então, por novos, agora zigóticos. Esse processo é conhecido por transição materno-zigótica (MZT) (HAMATANI et al., 2004). Os resultados de HE et al. (2010) sugerem que o momento em que ocorre a MZT é diferente entre camundongos e humanos, representada pela primeira mudança no padrão de 


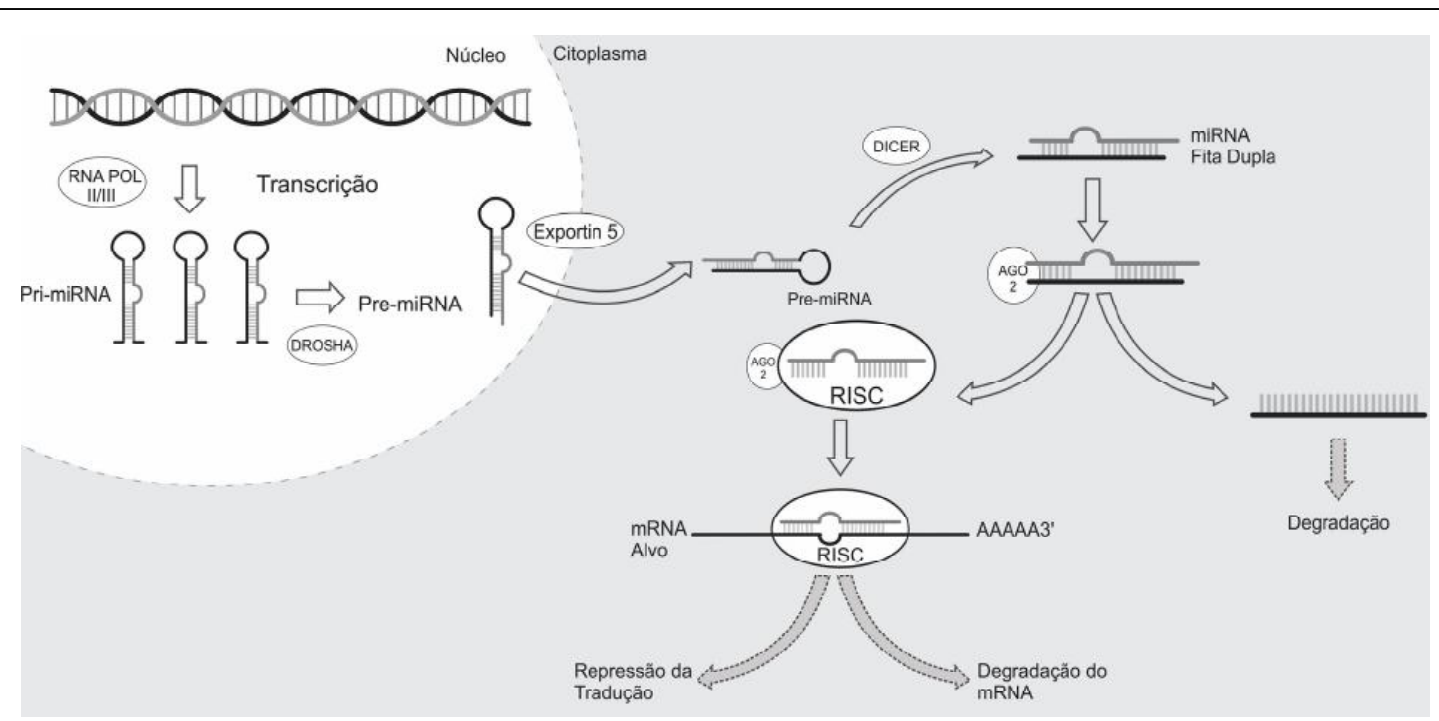

Figura 1 - Esquema da biogênese e atuação dos miRNAs. A enzima RNA polimerase II realiza a transcrição dos microRNAs primários (pri-miRNA). O complexo enzimático Drosha cliva os grampos formando precursores do miRNA (pre-miRNA), os quais são carreados ao citoplasma e associados ao complexo Exportin-5-Ran-GTP-dependent (Exportin 5). No citoplasma, o pre-miRNA é clivado pelo complexo enzimático Dicer, perdendo a configuração em grampo. O miRNA fita-dupla formado associa-se à proteína Argonauta 2 e uma das fitas é acoplada ao complexo de proteínas que reprime a expressão do gene alvo (RISC), enquanto a outra é degradada. O RISC, contendo o microRNA, liga-se ao mRNA-alvo, reprimindo a sua tradução ou promovendo a sua degradação.

expressão gênica (da primeira para a segunda etapa). A segunda mudança no padrão de expressão gênica sugere diferenças no controle do desenvolvimento préimplantacional e controle da implantação entre camundongos e humanos.

Essa variação na expressão gênica em função da espécie animal e tempo de desenvolvimento não é somente verificada em sequências codificantes, pois microRNAs também apresentam diferentes perfis de expressão ao longo da embriogênese. Em bovinos, segundo TESFAYE et al. (2009), miR-125a apresenta seu nível mais baixo de expressão em oócitos, o mais alto no estágio de quatro células e um leve declínio até a fase de blastocisto, no entanto, miR-25 apresenta um perfil de expressão oposto a este. O miR-127 e miR145 tem seu nível mais alto de expressão no embrião de oito células, com relativa baixa expressão antes e após este estágio. O miR-208 e miR-496 apresentam uma tendência de incremento nos níveis de expressão ao longo dos estágios pré-implantacionais com um pequeno decréscimo na fase de blastocisto, entretanto, miR-208 apresenta níveis superiores de expressão.

Dos 49 miRNAs descritos por COUTINHO et al. (2007), em embriões bovinos, no dia 30 do desenvolvimento, apenas nove são comuns aos encontrados por CASTRO et al. (2010) no embrião do dia 17 , sugerindo que, durante o desenvolvimento embrionário, ocorrem, pelo menos, duas fases com perfis diferentes de expressão de miRNAs. A primeira durante a ativação do genoma zigótico e a segunda em torno da implantação, determinando pools de miRNA distintos em função do tempo de desenvolvimento embrionário (CASTRO et al., 2010).

MicroRNAs são importantes para o desenvolvimento embrionário

Um indicativo da importância dos miRNAs no desenvolvimento embrionário consiste no fato de que, em Drosophila melanogaster, há maior expressão de microRNAs em tecidos embrionários do que em adultos (YU et al., 2007). A primeira evidência direta da ação de microRNAs no desenvolvimento embrionário inicial deu-se mediante o desenvolvimento de embriões knockout para Dicer e Argonauta 2. Esses embriões morreram antes do oitavo dia de desenvolvimento e não forneceram linhagem alguma de célula-tronco (BERNSTEIN et al., 2003; LIU et al., 2004).

Camundongos knockout para a enzima Dicer - responsável pela maturação citoplasmática dos miRNAs - demonstraram um incremento nos níveis de mais de $1 / 3$ dos genes expressos em oócitos, muitos deles provavelmente importantes para o desenvolvimento inicial, ocasionando defeitos na progressão meiótica em oócitos e na clivagem do 
embrião após a fertilização, inviabilizando o desenvolvimento embrionário (MURCHISON et al., 2007; TANG et al., 2007).

Proteínas e mRNAs maternos, como o Hlfoo (codificante para uma proteína da família das histonas) e o Msy2 (codificante para outra proteína com função estrutural para o genoma) colaboram para a transição materno-zigótica durante os primeiros estágios do desenvolvimento embrionário dos mamíferos e posteriormente não são mais expressos. Esses e outros mRNAs maternos devem ser degradados durante o desenvolvimento inicial e esse processo deve coincidir com a ativação da expressão gênica do zigoto (HE et al., 2010). Estudos sugerem que o momento exato do desenvolvimento em que ocorre a ativação do genoma zigótico e a degradação de transcritos maternos varia entre as espécies.

Em camundongos, a transição ocorre entre o zigoto e a primeira clivagem do embrião, enquanto no desenvolvimento humano ocorre entre a segunda e a terceira divisão embrionária; em bovinos, após a terceira clivagem (NIEMANN et al., 2007). Segundo HYTTEL et al. (2000), existem diferenças na expressão de genes codificantes para RNAs ribossômicos e proteínas organizadoras do nucléolo entre suínos e bovinos, podendo a ativação desses genes ser considerada um marcador para a ativação do genoma zigótico. O processo de degradação dos mRNAs maternos ainda não está bem esclarecido em mamíferos, no entanto, em Danio rerio (peixe paulistinha ou zebrafish), o miRNA miR-430 é transcrito durante a expressão inicial do genoma embrionário e auxilia na eliminação de centenas de mRNAs maternos, acelerando a transição entre os estágios do desenvolvimento (GIRALDEZ et al., 2006).

Segundo CASTRO et al. (2010), dois miRNAs, miR-30d e miR-26a, altamente expressos durante o alongamento trofoblástico em embriões bovinos, produzidos in vitro (PIV), interagem com a proteína TKDP, envolvida com o reconhecimento da prenhez. Em embriões clonados, a expressão aberrante de tais miRNAs está relacionada com falhas na implantação do embrião (CASTRO et al., 2010). Na tabela 1, estão descritos os principais miRNAs envolvidos no desenvolvimento embrionário.

MicroRNAs influenciam a maturação do oócito e a transição materno-zigótica

Genes expressos especificamente em oócitos apresentam importantes funções na foliculogênese e no desenvolvimento inicial do embrião (ZHENG \& DEAN, 2007), assim como os miRNAs (CARLETTI \& CHRISTENSON, 2009; ZHAO \& RAJKOVIC, 2008). Em bovinos, a expressão diferencial de miRNAs ao longo dos diferentes estágios de maturação de oócitos sugere seu envolvimento em tal processo (TESFAYE et al., 2009; HOELKER et al., 2010). A maior parte dos miRNAs presentes no zigoto é de origem materna e são herdados juntamente com o oócito. A ausência deles impossibilita a primeira divisão zigótica, determinando a inviabilidade do embrião (TANG et al., 2007). Em camundongos, os mais abundantes miRNAs maternos são os da família let-7, que regulam desde a oogênese até o desenvolvimento

Tabela 1 - Principais microRNAs envolvidos no desenvolvimento embrionário de diferentes espécies e sua respectiva função.

\begin{tabular}{|c|c|c|c|}
\hline MicroRNA & Espécie & Função & Referência \\
\hline Lin-4 & C. elegans & Tempo de desenvolvimento. & LEE et al., 1993 \\
\hline Let-7 (Família) & Humana & $\begin{array}{l}\begin{array}{l}\text { Proliferação e diferenciação celular durante } \\
\text { desenvolvimento. }\end{array} \\
\text {. }\end{array}$ & DING et al. ,2008 \\
\hline $\operatorname{miR}-430$ & D. rerio & Eliminação de mRNAs maternos. & GIRALDEZ et al., 2006 \\
\hline miR-30d & Bovina & Reconhecimento de prenhez e sucesso na implantação. & CASTRO et al., 2010 \\
\hline $\operatorname{miR}-26^{a}$ & Bovina & Reconhecimento de prenhez. & CASTRO et al., 2010 \\
\hline miR-290 (Família) & Mus musculus & $\begin{array}{l}\text { Manutenção da pluripotência em células-tronco } \\
\text { embrionárias (ESC). }\end{array}$ & SINKKONEN et al., 2008 \\
\hline miR-17-92 (Família) & Rattus rattus & $\begin{array}{l}\text { Proliferação e diferenciação celular durante } \\
\text { desenvolvimento. }\end{array}$ & $\begin{array}{l}\text { CHEN et al., } 2007 \text { / } \\
\text { HAYASHI et al., } 2008\end{array}$ \\
\hline miR-134 & R. rattus & Diferenciação de ESCs. & TAY et al., 2008 \\
\hline miR-296 & R. rattus & Diferenciação de ESCs. & TAY et al., 2008 \\
\hline $\operatorname{miR}-470$ & R. rattus & Diferenciação de ESCs. & TAY et al., 2008 \\
\hline miR-9 & M. musculus & Determinação de linhagens neurais derivadas de ESCs. & KRICHEVSKI et al., 2006 \\
\hline $\operatorname{miR}-124^{\mathrm{a}}$ & M. musculus & Determinação de linhagens neurais derivadas de ESCs. & KRICHEVSKI et al., 2006 \\
\hline miR-1 & M. musculus & Determinação de linhagens musculares derivadas de ESCs. & IVEY et al., 2008 \\
\hline miR-133 & M. musculus & Determinação de linhagens musculares derivadas de ESCs. & IVEY et al., 2008 \\
\hline
\end{tabular}


inicial do embrião (TANG et al., 2007). TRIPURANI et al. (2010) demonstraram que, em ovários fetais, os miRNAs bta-miR-424 e bta-miR-10b são altamente expressos em oócitos nos estágios de vesícula germinal e metáfase II, permanecendo em alta quantidade no embrião nas fases subsequentes à fertilização até a fase de embrião com 16 células. Nas fases de mórula e blástula, apresentaram uma tendência ao decréscimo em suas concentrações, sugerindo que a presença de ambos no embrião é de origem materna e pode estar envolvida na MZT.

Esse padrão de expressão sofre mudanças durante o desenvolvimento embrionário inicial. Em ratos, o total de miRNAs sofre uma redução drástica durante a primeira divisão do zigoto, sugerindo que, assim como os mRNAs, os miRNAs maternos também sofram degradação durante as clivagens inicias. Embriões no estágio de quatro células apresentaram níveis até duas vezes superiores de miRNAs, sugerindo que a ativação do genoma zigótico provoca nova síntese de microRNAs, agora embrionários. Em camundongos, o grupo de miRNAs de maior expressão ao fim da segunda clivagem é o dos miR-290s, formado por oito miRNAs maduros - miR-290-5p, miR-290-3p, miR-291a, miR-291b, miR-292, miR293, miR-294 e miR295. Comparado ao estágio de embrião com dois blastômeros, o nível de miR-290 chega a ser 15 vezes superior ao final da segunda clivagem e 24 vezes superior ao final da terceira clivagem (embrião com oito blastômeros) (TANG et al., 2007). SINKKONEN et al. (2008) demonstraram que os miRNAs do grupo miR290 atuam preferencialmente na manutenção do estado pluripotente das células-tronco embrionárias cultivadas in vitro.

MicroRNAs embrionários regulam o estado pluripotente e a diferenciação celular durante o desenvolvimento inicial

O estado indiferenciado de células embrionárias é mantido pela ação de fatores de transcrição. Alguns deles são específicos de células pluripotentes, como as da massa celular interna e células-tronco embrionárias e são comuns a seres humanos e camundongos. Oct4, Sox2 e Nanog são os principais fatores de transcrição presentes em células indiferenciadas embrionárias. Eles regulam a expressão de genes que atuam tanto na manutenção da pluripotencialidade e auto-renovação celular, quanto na diferenciação de tipos celulares extraembrionários, endodérmicos, mesodérmicos e ectodérmicos (LI, 2010; TAY et al., 2008).

Embora todos os mecanismos para a manutenção de células-tronco embrionárias ainda não estejam bem elucidados, estudos vêm demonstrando que uma série de miRNAs são preferencialmente expressos nessas células e desempenham papéis essenciais na regulação gênica, controlando a proliferação, pluripotência e diferenciação celular. Em humanos e ratos, por exemplo, o padrão de expressão de miRNAs sofre mudanças durante a diferenciação de células pluripotentes (BARROSO-DELJESUS et al., 2008; BIBIKOVA et al., 2008; CARD et al., 2008; SINKKONEN et al., 2008).

O grupo de miRNAs miR-290 apresenta um incremento na sua expressão durante o período de préimplantação do embrião e permanece alto enquanto não ocorrer diferenciação celular (HOUBAVIY et al., 2003, 2005). Estudos in vitro demonstraram que durante e após a diferenciação de células embrionárias, os níveis de expressão desse grupo de miRNAs diminui drasticamente. $O$ número aproximado de cópias de três dos mais abundantes miRNAs desse grupo por célulatronco embrionárias cultivadas in vitro é de $\sim 7600$ unidades. Esse número diminui para $\sim 10$ unidades por célula em tecidos diferenciados adultos ou embrionários (CHEN et al., 2007). A expressão desses miRNAs é perdida ao longo do desenvolvimento embrionário e não reaparece em nenhuma linhagem celular somática (STRAUSS et al., 2006). É interessante notar que os fatores de transcrição Oct4, Sox2 e Nanog associam-se a promotores de miRNAs expressos preferencialmente em células embrionárias pluripotentes, como o grupo dos miR-290, os quais estudos recentes demonstraram atuar na manutenção da pluripotencialidade e diferenciação desse tipo celular (MARSON et al., 2008; WANG et al., 2008; ZOVOILIS et al., 2009).

É muito interessante que a família miR-17-92 de miRNAs oncogênicos (formada pelos microRNAs miR-17a, miR-18a, miR-19a, miR-20a, miR-19b-1 e miR92-1), a qual se acreditava regular apenas o ciclo celular, também apresentou significativo decréscimo em sua expressão durante processos de diferenciação celular em embriões (CHEN et al., 2007). HAYASHI et al. (2008) relataram que durante o desenvolvimento de camundongos, as famílias miR-17-92 e miR-290 de miRNAs são altamente expressas em células germinativas primordiais e espermatogônias, sugerindo que esses miRNAs são necessários para o desenvolvimento inicial de células germinativas e para a espermatogênese. Essas duas famílias de miRNAs apresentam similaridade na organização genômica e no padrão de expressão, sugerindo que elas podem atuar como uma rede de regulação em células pluripotentes de mamíferos. HAWKINS \& MATZUK (2010) relataram o papel dos miRNAs na ovulogênese. De acordo com 
os autores, análises in silico indicam que o miR-93 atua no bloqueio da tradução de proteínas envolvidas na maturação do oócito.

Estudos demonstraram que Oct4, Sox2 e Nanog são alvo de miRNAs específicos. Após a indução da diferenciação em células-tronco embrionárias pluripotentes cultivadas in vitro, observou-se o incremento na expressão de três miRNAs: miR-134, miR-296 e miR-470. Análises in silico indicaram a presença de possíveis regiões complementares entre esses miRNAs e os fatores $O c t 4$, Sox2 e Nanog, sugerindo a atuação desses miRNAs nos processos de diferenciação celular através de regulação pós-transcricional da expressão de genes ligados à pluripotência (TAY et al., 2008).

MicroRNAs atuam na determinação da linhagem celular durante a organogênese

Muitos miRNAs participam da determinação de linhagens celulares no início da organogênese, como em processos de neurogênese e cardiogênese. KRICHEVSKY et al. (2006) demonstraram que diferentes miRNAs desempenham importantes funções na determinação de linhagens neurais derivadas de células de blastocistos. Foi demonstrado que um número significativo de miRNAs são co-induzidos durante a diferenciação de células neurais progenitoras em neurônios e astrócitos. A super-expressão de dois miRNAs específicos do sistema nervoso central, miR9 e miR-124a, em precursores neurais resultaram em redução no número de astrócitos formados, enquanto que o knockdown do miR-9 ou de ambos, miR-9 e miR124a, levou a uma redução na formação de neurônios. Outro estudo reforçou essa observação ao afirmar que miR-124 liga-se à região 3'UTR do transcrito do gene SCPI e reprime sua tradução. A diminuição da tradução de SCPI induz a neurogênese em embriões de galinhas e camundongos (VISVANATHAN et al., 2007).

MicroRNAs também atuam na cardiogênese. Os miRNAs miR-1 e miR-133 são específicos de músculos cardíacos e esqueléticos e sua expressão é regulada por uma série de fatores reguladores da diferenciação muscular. O miR-1 promove a diferenciação de células progenitoras cardíacas, enquanto o miR-133 inibe a especialização de mioblastos esqueléticos e promove a manutenção do seu estado proliferativo. Recentemente, IVEY et al. (2008) demonstraram que tanto miR-1 quanto miR-133 apresentam altos níveis de expressão em cardiomiócitos derivados de células-tronco embrionárias e são expressos em quantidades significativas nos primeiros estágios de diferenciação de células cardíacas mesodérmicas, derivadas de células pluripotentes durante a organogênese embrionária. Em corpos embrionários, a expressão de miR-1 e de miR133 induz a expressão de genes tipicamente mesodérmicos e suprime a diferenciação em tecidos ectodérmicos e endodérmicos. Contudo, esses dois microRNAs demonstram ter efeitos opostos durante o comprometimento de linhagens musculares, induzindo ou inibindo a diferenciação em músculos cardíacos e esqueléticos (LIU \& OLSON, 2010).

\section{CONCLUSÃO}

O fato de muitos microRNAs permanecerem conservados em diferentes espécies ao longo da evolução, além de seu notável papel no desenvolvimento embrionário, oferece um campo amplo para o desenvolvimento de pesquisas na área reprodutiva, visando ao melhoramento animal. A investigação das funções específicas de cada microRNA e seu perfil de expressão nas diferentes espécies de mamíferos pode contribuir para a resolução de muitos problemas referentes ao desenvolvimento embrionário e fetal, permitindo o incremento e o aperfeiçoamento de biotécnicas reprodutivas que visem à otimização dos processos produtivos.

\section{AGRADECIMENTOS}

V.F. Campos é aluno do Programa de Pós-graduação em Biotecnologia da UFPel e bolsista CAPES. G. Urtiaga é Bolsista de Iniciação Científica do CNPq. J.C. Deschamps é Bolsista de Produtividade em Pesquisa do CNPq.

\section{REFERÊNCIAS}

BARROSO-DELJESUS, A. et al. Embryonic stem cell-specific miR302-367 cluster: human gene structure and functional characterization of its core promoter. Molecular and Cellular Biology, v.28, p.6609-6619, 2008. Disponível em: $<$ http://mcb.asm.org/cgi/content/abstract/28/21/6609>. Acesso em: 18 nov. 2010. doi: doi:10.1128/MCB.00398-08.

BARTEL, D.P. MicroRNAs: genomics, biogenesis, mechanism, and function. Cell, v.116, p.281-297, 2004. Disponível em: http://www.cell.com/retrieve/pii/S0092867404000455. Acesso em: 18 nov. 2010. doi: 10.1016/S0092-8674(04)00045-5.

BERNSTEIN, E. et al. Dicer is essential for mouse development. Nature Genetics, v.35, p.215-217, 2003. Disponível em: $<$ http://www.nature.com/ng/journal/v35/n3/full/ng1253.html $>$. Acesso em: 18 nov. 2010. doi: 10.1038/ng1253.

BIBIKOVA, M. et al. Unraveling epigenetic regulation in embryonic stem cells. Cell Stem Cell, v.2, p.123-134, 2008. Disponível em: <http://www.cell.com/cell-stem-cell/abstract/ S1934-5909(08)00006-4>. Acesso em 18 nov. 2010. doi: 10.1016/j.stem.2008.01.005. 
CARD, D.A. et al. Oct4/Sox2-regulated miR-302 targets cyclin D1 in human embryonic stem cells. Molecular and Cellular Biology, v.28, p.6426-6438, 2008. Disponível em: <http:// mcb.asm.org/cgi/content/abstract/28/20/6426>. Acesso em: 18 nov. 2010. doi: 10.1128/MCB.00359-08.

CARLETTI, M.Z.; CHRISTENSON, L.K. MicroRnA in the ovary and female reproductive tract. Journal of Animal Science, v.87, p.E29-E38, 2009. Disponível em: <http:// jas.fass.org/cgi/content/short/jas.2008-1331v1>. Acesso em: 18 nov. 2010 . doi: $10.2527 /$ jas.2008-1331.

CASTRO, F.O. et al. MicroRNA expression profiling of elongated cloned and in vitro-fertilized bovine embryos. Theriogenology, v.73, p.71-85, 2010. Disponível em: <http:/ /www.theriojournal.com/article/S0093-691X(09)00389-6/ abstract $>$. Acesso em: 18 nov. 2010. doi: 10.1016/ j.theriogenology.2009.08.003.

CHEN, C. et al. Defining embryonic stem cell identity using differentiation-related microRNAs and their potential targets. Mammalian Genome, v.18, p.316-327, 2007. Disponível em: <http://www.springerlink.com/content/j551932277151401>. Acesso em: 18 nov. 2010. doi: 10.1007/s00335-007-9032-6.

COUTINHO, L.L. et al. Discovery and profiling of bovine microRNAs from immune-related and embryonic tissues. Physiological Genomics, v.29, p.35-43, 2007. Disponível em: <http://physiolgenomics.physiology.org/cgi/content/short/ 29/1/35>. Acesso em: 18 nov. 2010. doi: 10.1152/ physiolgenomics.00081.2006.

DING, X. C. et al. The let-7 microRNA interfaces extensively with the translation machinery to regulate cell differentiation. Cell Cycle, v.7, p.3083-3090, 2008. Disponível em: $<$ http:/ /www.landesbioscience.com/journals/6/article/6778/>. Acesso em: 18 nov. 2010.

DU, T.; ZAMORE, P.D. microPrimer: the biogenesis and function of microRNA. Development, v.132, p.4645-4652, 2005. Disponível em: $<\mathrm{http}: / /$ dev.biologists.org/content/132/ 21/4645.long>. Acesso em: 18 nov. 2010. doi: 10.1242/ dev. 02070

GIRALDEZ, A.J. et al. Zebrafish MiR-430 promotes deadenylation and clearance of maternal mRNAs. Science, v.312, p.75-79, 2006. Disponível em: <http://www.sciencemag.org/content/312/ 5770/75.abstract>. Acesso em: 18 nov. 2010. doi: 10.1126/ science. 1122689 .

HAMATANI, T. et al. Dynamics of global gene expression changes during mouse preimplantation development. Developmental Cell, v.6, p.117-131, 2004. Disponivel em: $<$ http://www.cell.com/developmental-cell/abstract/S15345807(03)00373-3>. Acesso em: 18 nov. 2010. doi: 10.1016/ S1534-5807(03)00373-3.

HAWKINS, S.M.; MATZUK, M.M. Oocyte-somatic cell communication an microRNA function in the ovary. Annales d'endocrinologie, v.71, p.144-148, 2010. Disponível em: $<$ http://www.em-consulte.com/article/251205>. Acesso em: 18 nov. 2010. doi: 10.1016/j.ando.2010.02.020.

HAYASHI, K. et al. MicroRNA biogenesis is required for mouse primordial germ cell development and spermatogenesis. PLoS One, v.3, p.e1738, 2008. Disponível em: < http://www.plosone.org/ article/info:doi/10.1371/journal.pone.0001738>. Acesso em: 18 nov. 2010. doi: 10.1371/journal.pone.0001738.

HE, K. et al. A comparative genome analysis of gene expression reveals different regulatory mechanisms between mouse and human embryo pre-implantation development. Reproductive Biology and Endocrinology, v.8, p.41, 2010. Disponivel em: <http://www.rbej.com/content/8/1/41>. Acesso em 18 nov. 2010. doi: $10.1186 / 1477-7827-8-41$.

HOELKER, M. et al. Importance of micro RNAs in developmental biology with respect to gametes and embryos. Acta Scientiae Veterinariae, v.38, p.s575-s589, 2010.

HOUBAVIY, H.B. et al. Characterization of a highly variable eutherian microRNA gene. RNA, v.11, p.1245-1257, 2005. Disponível em: <http://rnajournal.cshlp.org/content/11/8/ 1245.full>. Acesso em: 18 nov. 2010. doi: 10.1261/ rna.2890305.

HOUBAVIY, H.B. et al. Embryonic stem cell-specific MicroRNAs. Developmental Cell, v.5, p.351-358, 2003. Disponível em: <http://www.cell.com/developmental-cell/ retrieve/pii/S1534580703002272>. Acesso em: 18 nov. 2010. doi: $10.1016 / \mathrm{S} 1534-5807(03) 00227-2$.

IVEY, K.N. et al. MicroRNA regulation of cell lineages in mouse and human embryonic stem cells. Cell Stem Cell, v.2, p.219-229, 2008. Disponível em: <http://www.cell.com/cellstem-cell/abstract/S1934-5909(08)00057-X>. Acesso em: 18 nov. 2010. doi: 10.1016/j.stem.2008.01.016.

KIM, V.N. et al. Biogenesis of small RNAs in animals. Nature Reviews, v.10, p.126-139, 2009. Disponível em: <http:// www.nature.com/nrm/journal/v10/n2/full/nrm2632.html>. Acesso em: 18 nov. 2010. doi: 10.1038/nrm2632.

KRICHEVSKY, A.M. et al. Specific microRNAs modulate embryonic stem cell-derived neurogenesis. Stem Cells, v.24, p.857-864, 2006. Disponível em: <http:// onlinelibrary.wiley.com/doi/10.1634/stemcells.2005-0441/ abstract>. Acesso em: 18 nov. 2010 . doi: 10.1634/ stemcells.2005-0441.

LEE, R. C. et al. The C. elegans heterochronic gene lin-4 encodes small RNAs with antisense complementarity to lin14. Cell, v.75, p.843-854, 1993. Disponível em: <http:// www.cell.com/abstract/0092-8674(93)90529-Y>. Acesso em: 18 nov. 2010. doi: 10.1016/0092-8674(93)90529-Y.

LEE, Y. et al. The role of PACT in the RNA silencing pathway. EMBO Journal, v.25, p.522-532, 2006. Disponível em: <http://www.nature.com/emboj/journal/v25/n3/abs/ 7600942a.html>. Acesso em 18 nov. 2010. doi: 10.1038/ sj.emboj.7600942.

LEWIS, B.P. et al. Conserved seed pairing, often flanked by adenosines, indicates that thousands of human genes are microRNA targets. Cell, v.120, p.15-20, 2005. Disponível em: <http://www.cell.com/abstract/S0092-8674(04)01260-7>. Acesso em: 18 nov. 2010. doi: 10.1016/j.cell.2004.12.035.

LI, Y.Q. Master stem cell transcription factors and signaling regulation. Cell Reprogramming, v.12, p.3-13, 2010. Disponível em: <http://www.liebertonline.com/doi/abs/10.1089/ cell.2009.0033>. Acesso em: 18 nov. 2010. doi: 10.1089/ cell.2009.0033. 
LIU, C.; ZHAO, X. MicroRNAs in adult and embryonic neurogenesis. Neuromolecular Medicine, v.11, p.141-152, 2009. Disponível em: <http://www.springerlink.com/content/ 08877147327329g2/>. Acesso em: 18 nov. 2010. doi: 10.1007/ s12017-009-8077-y.

LIU, J. et al. Argonaute2 is the catalytic engine of mammalian RNAi. Science, v.305, p.1437-1441, 2004. Disponível em: $<$ http://www.sciencemag.org/content/305/5689/1437.abstract $>$. Acesso em: 18 nov. 2010. doi: 10.1126/science.1102513.

LIU, N.; OLSON E.N. MicroRNA regulatory networks in cardiovascular development. Developmental Cell, v.18, p.510-525, 2010. Disponível em: <http://www.cell.com/ developmental-cell/abstract/S1534-5807(10)00148-6>. Acesso em: 18 nov. 2010. doi: 10.1016/j.devcel.2010.03.010.

MARSON, A. et al. Connecting microRNA genes to the core transcriptional regulatory circuitry of embryonic stem cells. Cell, v.134, p.521-533, 2008. Disponível em: <http:// www.cell.com/abstract/S0092-8674(08)00938-0>. Acesso em: 18 nov. 2010 . doi: $10.1016 /$ j.cell.2008.07.020.

MURCHISON, E. P. et al. Critical roles for Dicer in the female germline. Genes \& Development, v.21, p.682-693, 2007. Disponível em: <http://genesdev.cshlp.org/content/21/6/ 682.short>. Acesso em: 18 nov. 2010. doi: 10.1101/ gad.1521307.

NICOLI, S. et al. MicroRNA-mediated integration of haemodynamics and Vegf signalling during angiogenesis. Nature, v.464, p.1196-1200, 2010. Disponível em: <http:// www.nature.com/nature/journal/v464/n 7292/full/ nature08889.html>. Acesso em: 18 nov. 2010. doi: 10.1038/ nature 0888 .

NIEMANN, H. et al. Application of DNA array technology to mammalian embryos. Theriogenology, v.68, Suppl.1, p.S165S177, 2007. Disponível em: <http://www.theriojournal.com/ article/S0093-691X(07)00267-1/abstract>. Acesso em: 18 nov. 2010. doi: 10.1016/j.theriogenology.2007.05.041.

OKADA, C. et al. A high-resolution structure of the premicroRNA nuclear export machinery. Science, v.326, p.12751279, 2009. Disponível em: <http://www.sciencemag.org/ content/326/5957/1275.short>. Acesso em: 18 nov. 2010. doi: $10.1126 /$ science. 1178705 .

PASQUINELLI, A. E. et al. Conservation of the sequence and temporal expression of let-7 heterochronic regulatory RNA. Nature, v.408, p.86-89, 2000. Disponível em: <http:// www.nature.com/nature/journal/v $408 / \mathrm{n} 6808 / \mathrm{fu} 11 /$ 408086a0.html>. Acesso em: 18 nov. 2010. doi: 10.1038/ 35040556 .

REINHART, B. J. et al. The 21-nucleotide let-7 RNA regulates developmental timing in Caenorhabditis elegans. Nature, v.403, p.901-906, 2000. Disponível em: <http:// www.nature.com/nature/journal/v $403 /$ n $6772 /$ full/ 403901a0.html>. Acesso em: 18 nov. 2010. doi: 10.1038/ 35002607 .

REN, J. et al. MicroRNA and gene expression patterns in the differentiation of human embryonic stem cells. Journal of Translational Medicine, v.7, p.20, 2009. Disponível em: $<$ http://www.translational-medicine.com/content/7/1/20>. Acesso em: 18 nov 2010. doi: 10.1186/1479-5876-7-20.
RUBY, J.G. et al. Intronic microRNA precursors that bypass Drosha processing. Nature, v.448, p.83-86, 2007. Disponível em: <http://www.nature.com/nature/journal/v448/n7149/abs/ nature 05983.html>. Acesso em: 18 nov. 2010. doi: 10.1038/ nature 05983.

SINKKONEN, L. et al. MicroRNAs control de novo DNA methylation through regulation of transcriptional repressors in mouse embryonic stem cells. Nature Structural \& Molecular Biology, v.15, p.259-267, 2008. Disponível em: $<\mathrm{http}: / /$ www.nature.com/nsmb/journal/v15/n3/abs/ nsmb.1391.html>. Acesso em: 18 nov. 2010. doi: 10.1038/ nsmb.1391.

SIOMI, H.; SIOMI, M.C. Posttranscriptional regulation of microRNA biogenesis in animals, Molecular Cell, v.38, p.323332, 2010. Disponível em: <http://www.cell.com/molecularcell/abstract/S1097-2765(10)00251-0>. Acesso em: 18 nov. 2010. doi: 10.1016/j.molcel.2010.03.013.

SMIRNOVA, L. et al. Regulation of miRNA expression during neural cell specification, European Journal of Neuroscience, v.21, p.1469-1477, 2005. Disponível em: $<\mathrm{http}$ //onlinelibrary.wiley.com/doi/10.1111/j.14609568.2005.03978.x/abstract>. Acesso em: 18 nov. 2010. doi: 10.1111/j.1460-9568.2005.03978.x.

STRAUSS, W.M. et al. Nonrestrictive developmental regulation of microRNA gene expression. Mammalian Genome, v.17, p.833-840, 2006. Disponível em: <http://www.springerlink.com/ content $/ \mathrm{j} 814 \mathrm{q} 05470512 \mathrm{t} 13 />$. Acesso em: 18 nov. 2010. doi: $10.1007 / \mathrm{s} 00335-006-0025-7$.

TANG, F. et al. Maternal microRNAs are essential for mouse zygotic development. Genes \& Development, v.21, p.644648, 2007. Disponível em: <http://genesdev.cshlp.org/content/ 21/6/644.abstract>. Acesso em: 18 nov. 2010. doi: 10.1101/ $\operatorname{gad} .418707$.

TAY, Y. et al. MicroRNAs to Nanog, Oct4 and Sox2 coding regions modulate embryonic stem cell differentiation. Nature, v.455, p.1124-1128, 2008. Disponível em: <http://www.nature.com/nature/ journal/v455/n7216/abs/nature07299.html >. Acesso em: 18 nov. 2010. doi: 10.1038/nature 07299 .

TESFAYE, D. et al. Identification and expression profiling of microRNAs during bovine oocyte maturation using heterologous approach. Molecular Reproduction and Development, v.76, p.665-677, 2009. Disponível em: <http:// onlinelibrary.wiley.com/doi/10.1002/mrd.21005/abstract $>$. Acesso em: 18 nov. 2010. doi: 10.1002/mrd.21005.

TRIPURANI, S.K. et al. Cloning and analysis of fetal ovary microRNAs in cattle. Animal Reproduction Science, v.120, p.16-22, 2010. Disponível em: <http://www.animalreproductionscience.com/article/ S0378-4320(10)00056-4/abstract>. Acesso em: 18 nov. 2010. doi: 10.1016/j.anireprosci.2010.03.001.

VISVANATHAN, J. et al. The microRNA miR-124 antagonizes the anti-neural REST/SCP1 pathway during embryonic CNS development. Genes \& Development, v.21, p.744-749, 2007. Disponível em: <http://genesdev.cshlp.org/content/21/7/ 744.abstract>. Acesso em: 18 nov. 2010. doi: 10.1101/ gad.1519107. 
WANG, Y. et al. Embryonic stem cell-specific microRNAs regulate the G1-S transition and promote rapid proliferation. Nature Genetics, v.40, p.1478-1483, 2008. Disponível em: $<$ http://www.nature.com/ng/journal/v40/n12/abs/ng.250.html $>$. Acesso em: 18 nov. 2010. doi: 10.1038/ng.250.

WIENHOLDS, E. et al. MicroRNA expression in zebrafish embryonic development. Science, v.309, p.310-311, 2005. Disponível em: <http://www.sciencemag.org/content/309/5732/ 310.abstract $>$. Acesso em: 18 nov. 2010. doi: 10.1126/ science.1114519.

WINTER, J. et al. Many roads to maturity: microRNA biogenesis pathways and their regulation. Nature Cell Biology, v.11, p.228-234, 2009. Disponível em: <http:// www.nature.com/ncb/journal/v11/n3/abs/ncb0309-228.html $>$. Acesso em: 18 nov. 2010. doi: 10.1038/ncb0309-228.

YU, Z. et al. Global analysis of microRNA target gene expression reveals that miRNA targets are lower expressed in mature mouse and Drosophila tissues than in the embryos. Nucleic Acids Research, v.35, p.152-164, 2007. Disponível em: <http://nar.oxfordjournals.org/content/35/1/152>. Acesso em: 18 nov. 2010 . doi: $10.1093 /$ nar/gkl1032.

ZHAO, H.; RAJKOVIC, A. MicroRNAs and mammalian ovarian development. Seminars in Reproductive Medicine, v.26, p.461-468, 2008. Disponível em: <https://www.thiemeconnect.com/DOI/DOI?10.1055/s-0028-1096126>. Acesso em: 18 nov. 2010 . doi: $10.1055 / \mathrm{s}-0028-1096126$.

ZHENG, P.; DEAN, J. Oocyte-specific genes affect folliculogenesis, fertilization, and early development. Seminars in Reproductive Medicine, v.25, p.243-251, 2007. Disponível em: $<$ https://www.thieme-connect.com/DOI/ DOI? 10.1055/s-2007-980218>. Acesso em: 18 nov. 2010. doi: $10.1055 / \mathrm{s}-2007-980218$.

ZOVOILIS, A. et al. Members of the miR-290 cluster modulate in vitro differentiation of mouse embryonic stem cells. Differentiation, v.78, p.69-78, 2009. Disponível em: $<$ http:/ /dx.doi.org/10.1016/j.diff.2009.06.003>. Acesso em: 18 nov. 2010. doi: $10.1016 / j$.diff.2009.06.003. 